\title{
Serviço de informação como fator de vantagem competitiva nas organizações
}

\author{
Gregório Jean Varvakis Rados, \\ Danielly Oliveira Inomata, \\ Dorzeli Salete Trzeciak, \\ Maurício Cordeiro Manhães \\ Universidade Federal de Santa Catarina - UFSC, Brasil
}

ARTICLE

\begin{abstract}
Resumo
O presente artigo objetiva discutir a relevância dos serviços de informação como fator de vantagem competitiva para as organizações, com foco no processo de Inteligência Competitiva. Trata-se de um estudo exploratório, com abordagem qualitativa, que utiliza a pesquisa bibliográfica como procedimento técnico para o levantamento dos dados. Trabalha-se com base nos aportes teóricos da Ciência da Informação; em especial, da Gestão da informação, tendo como perspectiva a existência de um processo sistemático de planejamento, coleta, análise e disseminação de informações para auxiliar na tomada de decisão das organizações. Discute-se que, para as atividades de análise e disseminação da informação existem outputs que podem ser chamados de serviços informacionais, cuja finalidade é identificar as necessidades de informação e garantir a disponibilidade e o acesso à informação no formato e tempo adequados. Os resultados indicam que: informação e conhecimento são insumos essenciais ao processo decisório das organizações; no processo de Inteligência Competitiva as etapas de análise e disseminação são as mais críticas, e devem ser trabalhadas no sentido de garantir o acesso às informações para a ação; as organizações têm dificuldades para processar e usar informações e devem, portanto, priorizar consumo e não estoque; os serviços de informação agregam valor ao processo de Inteligência Competitiva, contribuindo para a competitividade da organização. Conclui que os serviços de informação são indispensáveis para que os processos de IC possam agregar valor e, consequentemente, impactar positivamente as ações da organização.
\end{abstract}

Palabras clave

Serviços de informação ; Inteligência competitiva ; Vantagem competitiva

\section{Service information as advantage of competitive factor in organizations}

\begin{abstract}
This article aims to discuss the relevance of information services as a competitive advantage factor for organizations, focusing on Competitive Intelligence process. This is an exploratory study with a qualitative approach, which uses literature as a technical procedure for the collection of data. The work is based on theoretical studies of Information Science; in particular, information management, with the perspective that there is a systematic process of planning, collection, analysis and dissemination of information to assist in decision-making organizations. It is argued that, for the activities of analysis and dissemination of information are outputs that can be called information services, whose purpose is to identify the information needs and ensure availability and access to information in the appropriate format and time. The results indicate that: information and knowledge are essential inputs to decision-making organizations; the Competitive Intelligence process steps of analysis and dissemination are the most critical, and must be worked to ensure access to information for action; organizations have difficulties to process and use information and should therefore prioritize consumption and no inventory; information services add value to the Competitive Intelligence process, contributing to the competitiveness of the organization. Concludes that the information services are indispensable for the IC processes can add value and hence positively impact the organization's actions.
\end{abstract}

Keywords

Information services ; Competitive intelligence ; Competitive advantage 


\section{Introdução}

A estratégia adotada para a administração de organizações é considerada basilar no conceito de vantagem competitiva. Por isso, diversas áreas acadêmicas passaram a estudar este conceito, exploração essa que também vem sendo realizada pela Ciência da Informação.

Com base no que aponta a literatura visitada neste artigo, existe um processo sistemático (planejar, coletar, analisar e disseminar informações), legal e ético, que tem como um dos seus resultados um produto, para apoiar a tomada de decisão e, ao mesmo tempo, direcionar as estratégias e as operações de uma organização (KAHANER, 1998; TARAPANOFF, 2006).

Nesse contexto, a inteligência competitiva (IC) pode ser entendida como um processo pelo qual as organizações reúnem ativamente informações sobre concorrentes e ambiente competitivo, capturando e utilizando informação estratégica para a tomada de decisão, para os processos de planejamento e melhoria de desempenho empresarial (BADR; MADDEN; WRIGHT, 2006; FLEISHER; WRIGHT, 2009).

O objetivo deste artigo é o de discutir os serviços de informação como fator de vantagem competitiva nas organizações, com foco no conceito de IC. Para isso, utiliza como base os aportes teóricos da Ciência da Informação; em especial, da Gestão da informação.

O artigo está organizado em introdução; metodologia para caracterizar a pesquisa e os procedimentos adotados para a revisão exploratória da literatura; resgate bibliográfico para caracterizar os serviços de informação e a inteligência competitiva; contribuições sobre a relevância dos serviços de informação como vantagem competitiva para as organizações e; conclusões.

\section{Metodologia}

Quanto aos objetivos, a metodologia empregada foi a pesquisa exploratória, indicada para estudar um problema com vistas a torná-lo explícito (GIL, 2002), uma vez que essa pesquisa se dedica a discutir a IC sob a perspectiva de que os serviços de informação sustentam os resultados dos processos de IC e podem ser considerados fator de vantagem competitiva nas organizações.

A abordagem metodológica adotada neste trabalho é essencialmente qualitativa. E do ponto de vista dos procedimentos técnicos trata-se de uma pesquisa bibliográfica. Realizou-se busca exploratória nas bases de dados Scopus, Web of Science, Library \& Information Science Abstracts (LISA) e na Base de Dados Referencial de Artigos de periódicos em Ciência da Informação (BRAPCI), com intenção de localizar textos para fundamentar este trabalho.

No Brasil, a área da Ciência da Informação tem se dedicado a estudos sobre IC, a julgar pela contribuição dos bibliotecários e/ou cientistas da informação para essa temática, como mostra o estudo de Souza e Nassif (2012). E com base na identificação de pesquisas com o descritor "Inteligência Competitiva" (nos campos de título, resumo e palavras-chave) a $\mathrm{BRAPCl}$ mostra que na década de 90 somavam 13 o número de artigos sobre a temática, e a partir dos anos 2000 já somam mais de 60 artigos (BRAPCl, 2016).

No cenário mundial, até início dos anos 2000, a inteligência competitiva era um tema tratado sob diferentes abordagens, como destacou Menezes (2005), além dos aspectos tecnológicos (uso da internet), processo (coleta de informações formal e informal, tratamento das informações), métodos, técnicas e ferramentas para o monitoramento e análise de informações, iniciou-se os questionamentos quanto a intervenção humana no tratamento da informação.

Portanto, conclui que uma análise inteligente de informação exige, além da habilidade em recuperar a informação, também organizar as fontes de informação, verificar tendências, irregularidades e a capacidade de descobrir relações significativas para chegar a descobertas e conclusões que agreguem valor à organização (MENEZES, 2005).

Com a perspectiva de agregação de valor, neste trabalho utiliza-se como premissa: os serviços de informação sustentam processos de inteligência que contribuem para tornar uma organização mais competitiva. 


\section{Serviços de informação}

A capacidade de uma informação em reduzir incertezas está relacionada com a prontidão no seu fornecimento (CARVALHO, 2006). Logo, uma informação que não é fornecida em tempo hábil para a tomada de decisão, perde o seu valor. Desta forma, a informação desempenha papel estratégico, servindo de insumo à produção e ao gerenciamento dos recursos produtivos, sinalizando a importância da criação de serviços de informação, pela possibilidade de utilização de informações úteis e relevantes, obtidas via fontes de informação especializadas, aquelas reconhecidas pelos seus métodos para encontrar, selecionar e difundir a informação.

O serviço de informação se desenvolveu, primeiramente, no campo das pesquisas científicas e industriais, até chegar à forma característica atual (FOSKETT, 1969). Neste campo, originou-se a ideia de atribuir a uma pessoa, a responsabilidade de organização do acervo de informações recém publicadas que seriam úteis aos próprios pesquisadores.

A referida busca de literatura não aponta uma definição amplamente aceita para serviços de informação (TRZECIAK, 2009; ROZADOS, 2006). O que se encontra são manifestações sobre suas funções e sua caracterização, e uma possível explicação para este fato pode ser que a palavra serviço, por si só, é particularmente ambígua (ROZADOS, 2006).

Para fins de ilustração quanto à ambiguidade do termo, Lovelock e Wright (2002, p. 5) definiram serviço como

um ato ou desempenho oferecido por uma parte a outra. Embora o processo possa estar ligado a um produto físico, o desempenho é essencialmente intangível e normalmente não resulta em propriedade de nenhum dos fatores de produção.

Como uma atualização dessa definição, para os objetivos deste artigo, adota-se a definição elaborada a partir da lógica serviço-dominante, na qual serviço (VARGO; LUSCH, 2007, p. 26):

[...] é definido como a aplicação de competências especializadas (recurso operante conhecimentos e habilidades), através de atos, processos e performances para o benefício de outra ou da própria entidade.

Desta forma, com base também nas diretrizes da OCDEi, a inovação de serviços informacionais pode ser entendida como a aplicação de competências especializadas para a introdução de serviços novos ou significativamente melhorados, embebidos em artefatos comercializáveis. A partir dessa perspectiva, os serviços informacionais passam a ter maior relevância organizacional, pois permitem gerar uma gama de produtos estratégicos e exigem maiores níveis de conhecimento especializados (INOMATA et al., 2014).

Rozados (2006), ao tratar do UNISISTii, define os serviços de informação considerando sua função principal, que é a de servir de enlace entre uma população particular de usuários e o universo dos recursos de informação, tanto em forma impressa quanto não impressa. Para o UNISIST os papeis dos serviços de informação são: passivos, em que a função de um serviço de informação é garantir que qualquer informação solicitada por um usuário esteja à sua disposição, dentro do possível, no momento em que for requerida e; ativos, em que a função de um serviço de informação é a de alertar os usuários em relação aos documentos ou dados que possam ser de seu interesse.

A principal função dos serviços de informação consiste na identificação das necessidades, promoção dos meios confiáveis de captar e manipular os dados, além de promover o acesso à informação, tanto para a gerência, que planeja como para o operacional que executa (BORGES; CARVALHO, 1998). O principal objetivo do serviço de informação é conseguir que todas as necessidades de informação, previstas ou não pelo beneficiário final, sejam satisfeitas (ROZADOS, 2006).

Para Fitzsimmons e Fitzsimmons (2014), é crescente a oferta de serviços informacionais no mercado atual, o qual é impulsionado pelo avanço das TIC. Essa relação entre a oferta e a demanda de serviços informacionais acabou gerando inovações tecnológicas de produto e processo de serviços, e são elas que estão ajudando a definir a estratégia competitiva de organizações. 


\subsection{Características dos serviços de informação}

Uma tentativa de capturar o conceito de serviço resultou do Modelo IHIP (acrônimo em inglês para os termos intangibility, heterogeneity, inseparability e perishability)iii, que é amplamente utilizado pelos estudiosos da área para definir serviço.

Essas características dos serviços são descritas por vários autores na literatura consultada (DHOLAKIA; MUNDORF; DHOLAKIA, 1997; SCHMENNER, 1999; GRÖNROOS, 2003; CORRÊA; CAON, 2008; GIANESI; CORREAA, 2009; FITZSIMMONS; FITZSIMMONS, 2014) de forma resumida:

a) intangibilidade: o serviço não pode ser tocado ou sentido e, apesar de poder estar associado a algo físico, o que o cliente busca é algo intangível. Esta característica está relacionada às experiências vivenciadas pelo cliente, havendo dificuldade para avaliar seus resultados e sua qualidade;

b) volatilidade: muitos dos serviços de informação não deixam vestígios físicos após utilizados;

c) presença e participação do cliente: é necessária a presença do cliente para que um serviço seja produzido, sendo ele uma parte ativa do processo e o elemento disparador da operação. O conhecimento, a experiência e a motivação do cliente podem afetar diretamente no desempenho do serviço;

d) produção e consumo simultâneos: não é possível estocar os serviços, visto que eles são produzidos e consumidos simultaneamente. Isso pode afetar a qualidade criada durante o contato que ocorre entre o cliente e o funcionário.

No entanto, esse modelo não é aceito como verdadeiro por todas as correntes de pesquisa, e está sempre sob questão (EDVARDSSON et al., 2005). Como, por exemplo, Edman (2009, p. 13) comenta sobre os questionamentos que essas características sofrem:

Outro ponto de crítica é o fato de que o modelo IHIP não é verdadeiro: Muitos serviços são a) dependentes de produtos tangíveis - o SMS no telefone celular, b) homogêneos - os serviços de internet, c) são produzidos e consumidos em ocasiões diferentes - os programas educacionais a distância, d) são armazenáveis - os serviços de muitos softwares.

Dholakia, Mundorf e Dholakia (1997) relatam que os serviços de informações apresentam características que singulares, tais como: serviço em rede: geralmente, esses serviços precisam de uma rede para atingir o usuário (podem ser públicas ou privadas, analógicas ou digitais, comutadas ou de via física, com ou sem fio, estreitas ou amplas, em termos capacidade de transmissão de informações); interatividade: muitos serviços de informação fornecem interatividade entre os usuários ou entre os usuários e bancos de informação; caráter externo da rede: os serviços em rede e a interatividade criam determinados tipos de exterioridade, exclusivos dos serviços de informação.

Os serviços de informação precisam se estruturar de modo a oferecer informação de alta qualidade, buscando compreender e interpretar as necessidades de informação dos usuários, além de averiguar se as necessidades apontadas pelos usuários foram atendidas de modo efetivo (TRZECIAK, 2009).

Na visão de Gontow (1997), as informações precisam facilitar a comunicação, a tomada de decisão e a ação. Esta colocação está alinhada ao conceito de conhecimento oferecido por Drucker (1999, p. 24-25), que o define como "informação em ação efetiva, focada em resultados".

Desta forma, como aponta Trzeciak (2009), ao planejar serviços de informação é necessário avaliar os resultados a serem alcançados, os elementos que influenciam de modo concreto sua viabilidade, tais como levantamento e antecipação das necessidades de informação, fontes de informação, disseminação, divulgação 
e uso dos serviços, softwares e hardwares para administrar conteúdos e o papel das pessoas que vão desenvolver os serviços de informação.

\subsection{Tipos de serviços de informação}

Nota-se, na literatura, que os serviços de informação possuem algumas diferenças entre si, dependendo das esferas de conhecimento a qual se relacionam (científico, tecnológico, industrial, negócios). Portanto, esses serviços recebem diferentes denominações, dependendo dos produtos que geram, tais como:

- serviços de referência: resolvem questões de resposta imediata e simples, de modo superficial (MERLO VEGA, 2000);

- serviços de informação bibliográfica: oferecem informações mais complexas e elaboradas, tais como relações bibliográficas e buscas em bases de dados (MERLO VEGA, 2000);

- serviços de informação tecnológica: se destinam a identificar, adquirir, processar e transmitir informação ou dados tecnológicos e fornecer um produto de informação que contribua para o processo de inovação tecnológica (SILVA, 2005).

No entanto, Rozados (2006) aponta que apesar de manterem características que as particularizam, estas diversas esferas tendem, cada vez mais, a interagir, atenuando suas fronteiras. Estas interações ficam evidentes frente ao contexto atual de information overflow, e um dos seus principais aspectos conhecido pela alcunha de BIG DATA. Na sequência são apresentados exemplos de serviços de informação.

Com base em Rozados (2006) destacam-se os seguintes tipos de serviços de informação: busca de informações bibliográficas em bancos de dados internacionais; orientação ao serviço de perguntas e respostas e ao uso de fontes; localização e obtenção de documentos; boletim mensal de alerta; resposta específica a consultas sobre tecnologia, mercados, negócios; estudos bibliográficos; pesquisa rápida de informações sobre parceiros industriais; fornecimento de dados financeiros; levantamento do estado da arte de uma dada tecnologia; estudos de diversificação, mercado, técnico-econômico, normalização e regulamentação de produtos e marcas, certificações, estudos de campo e multiclientes; pesquisas sobre licenças, patentes, marcas, equipamentos e fornecedores; pareceres de mercado e técnicos; auditoria tecnológica e de informação; monitoramento tecnológico; levantamentos técnicos e análises de mercado; repertório dos produtos fabricados num determinado local; treinamento, assistência e consultoria sobre temas variados; orientação à pesquisa e a fontes de informação; normalização de publicações; disseminação seletiva da informação (DSI); extensão tecnológica (redes de informação tecnológica); além da realização de seminários e eventos técnicos.

\section{Inteligencia competitiva}

Devido a questões ligadas à lucratividade, à competitividade e ainda à sobrevivência no mercado, o acesso à informação é uma necessidade estratégica das organizações (SCIP, 2006; GOMES; BRAGA, 2004). Neste contexto, destaca-se a IC como uma importante ferramenta para apoiar a estratégia da organização, devendo, portanto, estar totalmente integrada com a mesma, a fim de que os objetivos sejam alcançados ou novos rumos sejam traçados (TRZECIAK, 2009).

No Quadro 1 são apresentados alguns conceitos de IC, sob a perspectiva de autores que trabalham com o tema. 


\begin{tabular}{|l|l|}
\hline \multicolumn{1}{|c|}{ Autores } & \multicolumn{1}{|c|}{ Conceitos } \\
\hline Tyson (1998) & $\begin{array}{l}\text { Um processo sistemático que transforma bits e partes de informações } \\
\text { competitivas sobre posição competitiva atual, desempenho, pontos fortes } \\
\text { e fracos e intenções específicas para o futuro em conhecimento } \\
\text { estratégico para auxiliar na tomada de decisão. }\end{array}$ \\
\hline Miller (2000) & $\begin{array}{l}\text { Uma estratégia organizacional para descobrir o que ocorre no ambiente } \\
\text { de negócios. O conhecimento produzido oferece auxílios aos executivos } \\
\text { para tomar decisões em relação às vantagens sobre seus concorrentes. }\end{array}$ \\
\hline Tarapanoff (2001, p. 45) & $\begin{array}{l}\text { "Uma nova síntese teórica no tratamento da informação para a tomada } \\
\text { de decisão, uma metodologia que permite o monitoramento } \\
\text { informacional da ambiência e, quando sistematizado e analisado, a } \\
\text { tomada de decisão." }\end{array}$ \\
\hline Gomes e Braga (2004, p. & $\begin{array}{l}\text { "Um processo ético de identificação, coleta, tratamento, análise e } \\
\text { disseminação da informação estratégica para a organização, viabilizando } \\
\text { seu uso no processo decisório." }\end{array}$ \\
\hline ABRAICiv (2016) & $\begin{array}{l}\text { Um processo sistemático informacional proativo que conduz à melhor } \\
\text { tomada de decisão estratégica ou operacional, o qual visa descobrir as } \\
\text { forças que regem os negócios, reduzir o risco e conduzir o tomador de } \\
\text { decisão a agir antecipadamente, bem como proteger o conhecimento } \\
\text { gerado. }\end{array}$ \\
\hline
\end{tabular}

Fonte: Dados da pesquisa

Verifica-se, diante do exposto, que algumas abordagens são estratégicas, outras mais operacionais, porém, todas apresentam como objetivo central obter informações, principalmente do ambiente externo. Informações estas que devem, por meio de serviços de informação, ser coletadas, analisadas e disseminadas para subsidiar o processo de tomada de decisão, contribuindo para o aumento da competitividade da organização.

\subsection{Processo de inteligência competitiva}

Processo é um grupo de tarefas interligadas logicamente, que utilizam os recursos da organização para gerar os resultados definidos, de forma a apoiar os seus objetivos (HARRINGTON, 1994). Em IC, todo e qualquer processo tem como objetivo principal reunir informações sobre concorrentes e o ambiente competitivo, a fim de auxiliar na tomada de decisão, conforme foi apontado no item anterior.

De modo geral, as etapas que compõe o processo de IC vão desde a necessidade de compreender determinado assunto, passando pela coleta de dados, análise, contextualização e disseminação das informações e, por fim, a avaliação dos resultados obtidos.

Amaral et al. (2005) apresenta o detalhamento das etapas do processo de IC:

- determinação de necessidades de informação: etapa destinada à compreensão das reais necessidades de inteligência do cliente e da organização, a fim de direcionar corretamente as atividades que serão executadas ao longo do tempo. Organiza-se também, a forma do trabalho, incluindo previsão de atividades, fontes de informação, métodos analíticos, equipe, prazos e demais recursos;

- coleta das informações: etapa que compreende a coleta e organização das matérias primas do processo de IC (dados e informações); 
- $\quad$ análise das informações: abrange a análise das informações já coletadas e tratadas para a elaboração dos produtos de inteligência, buscando responder às questões apontadas nas necessidades de informação;

- disseminação dos resultados: nessa etapa, os resultados do processo de IC são apresentados ao cliente e à organização;

- $\quad$ avaliação dos resultados: verifica a eficácia e a eficiência dos resultados e processos utilizados no trabalho, visando a melhoria futura e a consolidação de boas práticas.

Para auxiliar na execução das etapas apresentadas, Gomes e Braga (2004) apresentam várias ferramentas, tais como: modelo das cinco forças de Porter, fatores críticos de sucesso, SWOT, benchmarking, cenários, análise do setor, cadeia de valor, perfil do concorrente, análise dos stakeholders.

Destaca-se que, além destas ferramentas há outras disponíveis. No entanto, precisam ser utilizadas de acordo com a questão a ser resolvida. Trzeciak (2009) salienta que, por mais que se automatize o processo, somente o raciocínio humano consegue avaliar a real relevância e credibilidade das informações, agregando valor a sua formatação final.

Além das ferramentas mencionadas, existem os relatórios de coleta de informações, cuja função é auxiliar na recuperação rápida das informações e das fontes de coleta, tais como: mapa estratégico da informação (reconhece e cadastra informações internas ou externas associadas às competências das empresas); matriz de informações sobre a concorrência (mapeamento de informações sobre a concorrência, no que se refere a certos assuntos estratégicos); relatório de monitoramento das fontes primárias (registra a rede de relacionamento dos colaboradores da organização, a fim de coletar informações interessantes ao processo de inovação); relatório básico de coleta (registra informações originárias de consultas a fontes externas à organização) (ABREU et al., 2008).

Já os relatórios de análise de informações, aqueles que possuem maior valor agregado, apresentam elementos que podem subsidiar as tomadas de decisão. Como exemplos citam-se: newsletter: apresenta tanto informações estratégicas como táticas, de fontes internas e externas, funcionando como um sistema de alerta e não necessariamente envolve análise; minutas de impacto estratégico: semelhantes aos boletins de notícias, porém, identificam eventos de impacto estratégico ou tático à empresa e envolvem análise; análise de situação: apresentam resumos de assuntos estratégicos/chave, incluem análises detalhadas e consolidam os anteriores; análise do projeto/produto: relato de uma ou duas páginas que identificam a situação ou o assunto, com resumo das análises de suporte/chave e recomendação de ações para projetos ou produtos específicos; evolução de concorrente: registro da evolução do concorrente em termos de variáveis quantitativas de inovação e verificação de mudanças na estratégia e suas implicações no mercado (ABREU et al., 2008).

É importante ressaltar que, conforme as suas necessidades, a organização pode elaborar outros tipos de relatórios, ou até mesmo utilizar relatórios já existentes que, com algumas alterações, atendam às necessidades de informação identificadas. Desde que os produtos gerados com a análise tenham um valor agregado, e não simplesmente sejam um repasse das informações coletadas (FOSTER, 2008).

Outro ponto a ser destacado, é a etapa de disseminação, ou seja, a entrega da informação analisada, pois é importante que essas informações sejam distribuídas e estejam disponíveis para todos os níveis e/ou setores da organização, por meio de formatos adequados e em tempo hábil.

Nesse sentido, é fundamental que haja a avaliação de todo o processo de IC. Segundo Baierle et al. (2011), é necessário avaliar se o plano de inteligência criado foi eficiente, no tocante as informações criadas e no quanto atenderam as necessidades de informação identificadas e auxiliaram nas estratégias da organização.

\subsection{Sistemas e práticas de IC}

Os processos de IC, entendida como uma forma específica de serviço de informação, são parte constituinte de um sistema - um sistema de monitoramento - cujos elementos se relacionam, conforme Valetim et al. (2003), por meio de fluxos de informação (formais e informas) - os quais ocorrem nos ambientes internos e externos à organização - e na geração de uma terceira via: a estrutura informacional (geração de dados, informação e 
conhecimento). Miller (2002) destaca que da mesma forma que os dados são elementos constitutivos da informação, esta é base para a inteligência. Para complementar, de acordo com Drucker (1999), o conhecimento é informação efetiva para a obtenção de determinado resultado. Para o contexto deste artigo é necessário que se adote uma definição de trabalho para o conceito de inteligência. Desta forma, a definição adotada neste trabalho é a de que a "inteligência mede a habilidade de um agente para obter resultados em uma ampla gama de ambientes" (LEGG e HUTTER, 2007, p. 405).

A IC, no presente contexto, é entendida como um processo complexo que se configura numa autêntica engenharia de informação (SANTOS, 2007), no entanto, um sistema de IC pode ser simples, mas deve priorizar o resultado, ao longo do processamento da informação e deve agregar valor à tomada de decisão. Outro aspecto a ser destacado é que cada organização pode customizar os processos de IC conforme a cultura, negócio e política da empresa (VALENTIM et al., 2003).

Para o desenvolvimento dos processos de IC a infraestrutura da organização deve ser valorizada, tanto quanto o recurso humano, que é o executor da IC. Santos (2000) ao analisar métodos e ferramentas para o gerenciamento da IC aponta que:

\begin{abstract}
Os registros, na literatura, de fracassos de sistemas corporativos de informações, sejam eles grandes ou pequenos, simples ou complexos, apontam, como causa principal, o fato desses sistemas não privilegiarem em todas as suas fases a concepção, a implantação, a operação e o fator humano. A ênfase desses sistemas concentrou-se na tecnologia, como um fim em si mesmo (SANTOS, 2000, p. 2014).
\end{abstract}

Em observação aos processos de IC (determinação de necessidades de informação, coleta e análise das informações, disseminação e avaliação dos resultados), a tecnologia pode oferecer um suporte maior nas fases de coleta (quando se trata de informação pública) e disseminação, e o fator humano é muito mais evidente nos processos de planejamento da determinação de necessidades de informação, coleta (quando se trata de informações oriundas de fontes primárias) e análise.

No que tange às práticas de IC, Fleisher (2001) destaca que, embora comumente realizadas pelo departamento de pessoal e de marketing de uma organização, outros profissionais podem atuar com IC, tais como: bibliotecários e especialistas em informação - são frequentemente envolvidos com processos de coleta de dados de IC; decision-maker - utilizam normalmente a inteligência crítica que a IC precisa; analistas indivíduo que coleta informação e sabe dar sentido a isso; consultores - é crescente a indústria de consultoria em IC, e cresce também o número de consultores (de gestão da informação, consultores especialistas em IC); especialistas em estratégia e marketing (planners) - que particularmente são envolvidos com IC; pesquisadores - principalmente aqueles que trabalham com mercado e pesquisa de marketing.

Todos estes profissionais são analistas de IC. O analista de IC deve ter a habilidade de explorar as fontes de informação públicas para coletar informações que permitam orientar esses eventos (tomada de decisão, planejamento, melhoria de desempenho) na empresa (FLEISHER; WRIGHT, 2010). A competência do profissional atuante em IC deve estar atrelada a um conjunto de habilidades que vão desde o conhecimento técnico; o conhecimento linguístico específico de sua área de trabalho; a capacidade de se comunicar e transferir seus conhecimentos eficazmente (VALETIM et al., 2003; FLEISHER, 2001); a capacidade de utilizar ferramentas para análise de informação estratégica, como o uso de softwares infométricos de exploração e estruturação de informações (SANTOS, 2000) ou para apoiar as práticas de IC, como o uso de sistemas de gestão da informação (ROSSI; PASSARINI; FARIA, 2012); até a utilização de técnicas (como o modelo das 5 forças de Poter, SWOT, benchmarking, fatores críticos de sucesso, etc.) (SANTOS; NASSIF, 2012).

Fleisher (2001) detalha algumas atitudes e aptidões efetivas de IC:

- boa habilidade para observar e escutar - isso é valioso quando se precisa de uma informação. Especialmente útil em uma era de negócios globais é a capacidade de se comunicar em vários idiomas;

- criatividade - capacidade de localizar a informação que outros não conseguem encontrar; 
- $\quad$ persistência - significa não desistir mesmo quando os dez primeiros contatos não fornecem nenhuma pista;

- $\quad$ estratégia - saber planejar de forma eficiente uma tarefa de IC quando Ihe for designado;

- $\quad$ networking - saber localizar contatos quando Ihe for solicitado;

- $\quad$ habilidades relacionadas a informação - entender sobre bases de dados, bibliotecas, e softwares pertinentes para trabalhar com IC (planilhas, programas de análise estatística, habilidades de entrevista e escrita);

- $\quad$ experiência - ter experiência em IC, ter clareza nas perguntas e respostas, fazer uso de uma linguagem entendida por aqueles que procuram respostas.

Como destacado anteriormente, cada organização tem uma política de IC. Mundialmente, também é diferenciado o estilo de prática de IC, embora a escola estadunidense seja a pioneira na área.

Fleisher e Wright (2009) examinam as diferenças das práticas de IC entre Oriente (com dados da China e Japão) e Ocidente (dados dos Estados Unidos), e em linhas gerais discutem que as práticas de IC por executivos americanos são oriundas de fontes de informação provenientes, muito mais, de acervo técnico e publicações. Os executivos orientais se dedicam a coleta de informação legal, utilizando o que está em livre acesso e também utilizam como fontes de informação as pessoas e, de fato, são conhecidos por interagir e aprender por suas redes pessoais.

Outro aspecto já relatado por Herring (1992), é que as empresas japonesas globalmente competitivas utilizam fontes de informação formal e informal sistematicamente para a compreensão do mercado global, o que para Ikeya e Ishikawa (2001) é um reforço para a competitividade da empresa. Existe um processo de coletar informações oriundas de redes pessoais, que são disseminadas por meio de práticas organizacionais, fazendo uso da tecnologia moderna e sistema de informação para toda a empresa (NAKAGAWA, 1993 apud FLEISHER; WRIGHT, 2009).

Sobre a IC na China, Xie e Jin (2011) argumentam que há dois tipos de forças que impulsionam o seu crescimento: (i) pesquisas organizacionais sobre IC; e a (ii) autorreflexão sobre as atividades de IC nas empresas. Isso reforça os resultados verificados com a pesquisa empírica de Zhang (2008) em 415 empresas e entrevistas com 28 experts em IC: mais de $60 \%$ das grandes empresas da amostra tinham informações sobre a IC (FLEISHER; WRIGHT, 2009).

Especificamente na China, a gestão e as práticas organizacionais de IC ainda estavam em estado embrionário e desigual em comparação com outros países-nação, embora alguns avanços (criação da Society of Competitive Intelligence China, SCIC) tenham sido feitos nos últimos anos em relação a políticas governamentais e nas universidades, com relação a entrada de temáticas sobre liderança, processos de gestão, sistemas de negócios e IC (FLEISHER; WRIGHT, 2009);

Nos Estados Unidos, conforme destacam Fleisher e Wright (2009), as pesquisas sobre IC são muito mais desenvolvidas do que em outros países. A prática norte-americana de IC, em particular, tem sido adotada e explorada por várias empresas líderes, difundidas na literatura sobre IC por meio de demonstração de estudos de caso.

\section{Relevância dos serviços de informação como vantagem competitiva para as organizações}

As organizações que desejam ser bem sucedidas em seus processos de aprendizado e de inovação, na visão de Castro, Jannuzzi e Mattos (2007) devem empenhar-se de modo sistemático na criação e utilização de novas experiências e novos conhecimentos. No que tange às atividades de tratamento, análise e compartilhamento de informação e conhecimento, estas necessitam estar intimamente ligadas ao grau de qualidade e diferenciação da produção e, consequentemente, com o processo de inovação (TOMAÉL et al., 2006), pois a informação e o 
conhecimento são subsídios essenciais para a geração de ideias criativas, formadoras da base de recursos para a inovação.

O que se percebe é que, ao oferecer informação de qualidade às organizações, um serviço de informação pode contribuir para o planejamento de soluções, bem como fomentar um clima que favoreça a inovação e, consequentemente, a sua competitividade.

Os serviços de informação são elementos fundamentais de auxílio à geração de inovação, tornando-se parte dos recursos estratégicos da economia de um país. No entanto, apesar do valor da informação como geradora de conhecimento e da crescente produção tecnológica e cientifica, tomando como exemplo o Brasil, verificou-se que ainda se faz pouco uso destes recursos como fatores determinantes para atuar de maneira inovadora no mercado, principalmente no que se refere a micro e pequenas organizações (CASTRO; JANNUZZI; MATTOS, 2007). Talvez isso ocorra, pelo fato de que boa parte das organizações não possui uma cultura voltada ao uso da informação como recurso estratégico ou para agregar valor e transformá-la em vantagem competitiva (COSTA, 2003).

O alto valor agregado aos serviços de informação precisa envolver análise, adequação e geração de novas informações, de acordo com a necessidade dos usuários, buscando solucionar tanto problemas tecnológicos quanto gerenciais. Salienta-se que os serviços de informação precisam suprir as necessidades de informação das organizações, para que consigam sobreviver e se tornar mais competitivas no mercado, considerando, inclusive, a interação universidade-empresa como uma possível ação que pode contribuir para a competitividade do setor produtivo do país. Os serviços de informação que conseguem promover essa interação podem ser vistos como facilitadores para suprir as necessidades de informação científica e tecnológica (RAMOS; CARVALHO; CUNHA, 2006).

O investimento em serviços de informação pode possibilitar às instituições provedoras, o fornecimento de conhecimento sobre a dinâmica dos setores industriais e do ambiente empresarial e às instituições usuárias, maiores benefícios em relação ao seu desempenho, à sua capacidade de inovar e à garantia da sua competitividade. Desta forma, a oferta de serviços de informação, no atual contexto das políticas tecnológicas e industriais se constitui em estratégia fundamental para aumentar a competitividade do setor produtivo, por meio da melhoria da qualidade, da inovação tecnológica e do aumento da capacitação gerencial (SILVA; MARINHO, 2002).

Quanto a IC, como todo serviço de informação, implica no desenvolvimento da capacidade de identificação, sistematização e interpretação dos sinais externos da empresa, desempenhando um importante papel ao subsidiar a empresa na interação com outros atores do sistema de inovação, provocando ganhos em termos de aprendizagem e identificação de oportunidades, bem como a preservação de informações, conhecimento e projetos estratégicos (CANONGIA et al., 2004).

A habilidade de disseminar e compreender rapidamente o conteúdo da inteligência é, também, um fator essencial no ambiente dinâmico e competitivo onde as empresas se inserem. E neste caso, a tecnologia da informação é essencial para dar apoio a todo o processo, a fim de garantir acesso, armazenamento e disponibilização do conhecimento.

Usar estrategicamente a informação e o conhecimento acarreta em redução de custos e contribui para elevar a competitividade da organização e para agregar valor ao produto e/ou serviços ofertados pela empresa (COHEN, 2002). Sobre isso, Tomaél et al. (2006) destacam que a IC gera informações que possibilitam agregar valor aos produtos, processos e serviços existentes na organização, além de darem suporte à criação de estratégias competitivas, sustentando o processo de inovação.

Portanto, sugere-se que por meio do tratamento e análise das informações do ambiente onde atuam, as organizações podem antecipar mudanças e oportunidades, identificar as reais necessidades dos clientes, conhecer melhor os concorrentes, identificar tendências e, consequentemente, poderão se tornar mais competitivas. 


\section{Conclusão}

Como visto, tomou-se como premissa que os serviços de informação sustentam processos de inteligência que contribuem para tornar uma organização mais competitiva. As discussões levantadas convergem para alguns apontamentos e inferências, sendo:

- informação e conhecimentos são insumos essenciais ao processo de inovação na organização. No entanto, não eximem a organização de estabelecer de forma definida um processo específico de inovação;

- no processo de IC, a análise é geralmente considerada a etapa mais difícil do ciclo de IC (KAHANER, 1998), certamente pelo volume de informações que necessitam ser tratadas e organizadas para posterior disseminação (a etapa seguinte do ciclo de IC). Destaca-se que as etapas de análise e disseminação, são consideradas críticas para a IC e nos resultados dessas fases, encontra-se como saída os serviços de informação, os quais devem garantir o acesso à informação para agir;

- $\quad$ as organizações não têm dificuldades para coletar e armazenar informações para a tomada de decisão, as dificuldades maiores são para processar informação para o uso (SANTOS, 2000; CAPUANO et al., 2009), portanto, deve-se priorizar consumo e não estoque;

- a organização deve estar atenta para classificar e registrar, em repositórios de conhecimentos, as pesquisas realizadas em ciclos de inteligência anteriormente executados. Essa ação minimiza o tempo de novas coletas de informação, ao mesmo tempo em que facilita a localização de fontes analisadas pela equipe de IC. Essa ação não exclui o monitoramento de informações atuais e a localização de outras fontes.

Este artigo discutiu o serviço de informação, definido como um ato ou desempenho ofertado, com a exigência de competências especializadas (recurso operante - conhecimentos e habilidades) na produção de recursos informacionais que habilitem a um agente a obter resultados em uma ampla gama de ambientes, com intuito de identificar as necessidades de informação, garantir que a informação relevante esteja disponível para um determinado beneficiário e, continuamente, comunicar aos usuários do sistema dos serviços de informação que são ofertados, e com isso promover o acesso oportuno à informação. Nesta perspectiva, os serviços de informação são indispensáveis para que os processos de IC possam agregar valor e, consequentemente, impactar positivamente as ações da organização, a exemplo da inovação, do tempo de recuperação de informações estratégicas, no monitoramento da concorrência e no aumento da competitividade.

\section{Referências}

ABRAIC. ASSOCIAÇÃO BRASILEIRA DOS ANALISTAS DE INTELIGÊNCIA COMPETITIVA. [2016]. Disponível em: $<$ abraic. org.br>.

ABREU, A. F et al. Inteligência competitiva. In: CORAL, E.; OGLIARI, A.; ABREU, A. F. Gestão integrada da inovação: estratégia, organização e desenvolvimento de produtos. São Paulo: Atlas, 2008. Cap. 6, p. 113-135.

AMARAL, R. M. et al. Base de referências para o mapeamento de competências em inteligência competitiva. In: ABRAIC. Prêmio de inovação em Inteligência competitiva. Brasília: ABRAIC / FINEP, 2005. p. 69-97. Caderno 2.

BADR, A.; MADDEN, E.; WRIGHT, S. The contribution of $\mathrm{Cl}$ to the strategic decision making process: Empirical study of the European pharmaceutical industry. Journal of Competitive Intelligence \& Management, v. 3, n. 4, p. 15-35, 2006.

BAIERLE, I. C. et al. O ciclo da produção de inteligência como apoio à estratégia de tomada de decisão organizacional. Revista Produção Online. Florianópolis, SC, v.11, n. 4, p. 1086-1113, out./dez. 2011.

BORGES, M. E. N.; CARVALHO N. G. M. Produtos e serviços de informação para negócios no Brasil: características. Ciência da Informação, Brasília, v. 27, n. 1, p. 76-81, jan./abr. 1998.

CANONGIA, C. et al. Foresight, inteligência competitiva e gestão do conhecimento: instrumentos para a gestão da inovação. Gestão \& Produção, v. 11, n. 2, p. 231-238, maio/ago. 2004.

CAPUANO, E. A. et al. Inteligência competitiva e suas conexões epistemológicas com gestão da informação e do conhecimento. Ciência da Informação, Brasília, v. 38, n. 2, p. 19-34, maio/ago. 2009. Disponível em: $<$ http://www.scielo.br/scielo.php?script=sci_arttext\&pid=S0100-19652009000200002>. 
CARVALHO, E. L. Importância da gestão da informação para o processo decisório nas organizações. In: VALENTIM, M. L. P. (Org.). Informação, conhecimento e inteligência organizacional. 2. ed. Marília: FUNDEPE, 2006. cap. 5, p. 81-97.

CASTRO, A. C.; JANNUZZI, C. A. S. C.; MATTOS, F. A. M. Produção e disseminação de informação tecnológica: a atuação da Inova - Agencia de Inovação da UNICAMP. Transinformação, Campinas, v. 19, n. 3, p. 265-277, set./dez. 2007.

COELHO, G. M.; DOU, H. Inteligência competitiva e a formação de recursos humanos no Brasil. Revista de Biblioteconomia de Brasília, v. 23/24, n.4, p. 455-472, especial 1999/2000.

COHEN, M. F. Alguns aspectos do uso da informação na economia da informação. Ciência da Informação, Brasília, v. 31, n. 3, p. 23-36, set./dez. 2002.

COSTA, M. D. Procedimentos para aplicação de mapas semânticos como estratégia para criação do conhecimento organizacional. 2003. Tese (Doutorado em Engenharia de Produção) - Programa de Pós-Graduação em Engenharia de Produção, Universidade Federal de Santa Catarina, Florianópolis, 2003.

DHOLAKIA, N.; MUNDORF, N.; DHOLAKIA, R. R. Novos serviços de informação e comunicação: um quadro de referência estratégica. Ciência da Informação, Brasília, v. 26, n. 3, 1997.

DOU, H.; DOU JÚNIOR, J. M. Innovation management technology: experimental approach for small firms in a deprived environment. International Journal of Information Management, v. 19, p. 401-412, 1999.

DRUCKER, P. Sociedade pós-capitalista. São Paulo: Pioneira; São Paulo: Publifolha, 1999.

EDMAN, K. W. Exploring Overlaps and Differences in Service Dominant Logic and Design. Designforskning.no, p.1 - 12, 2009.

EDVARDSSON, B.; GUSTAFSSON, A.; ROOS, I. Service portraits in service research: a critical review. International Journal of Service Industry Management, v. 16, n. 1, p. 107-121, 2005.

FLEISHER, C. S. An introduction to the management and practice of competitive intelligence (CI). In. FLEISHER C. S.; BLENKHORN, D. L. (Eds.) Managing frontiers in competitive intelligence, 2001, p. 3-18.

FLEISHER, C. S.; WRIGHT, S. Examining differences in competitive intelligence practice: China, Japan, and the West. Thunderbird International Business Review, v. 51, n. 3, p. 249-261, 2009.

FOSKETT, D. J. Serviço de informação em bibliotecas. São Paulo: Polígono, 1969.

FOSTER A. Business information review. SAGE Publications, Los Angeles, v. 25, n. 1, p. 13-31, 2008.

GIL, A. C. Como elaborar projetos de pesquisa. 4. ed. São Paulo, SP: Atlas, 2002.

GOMES, E.; BRAGA, F. Inteligência competitiva: como transformar informação em um negócio lucrativo. 2. ed. rev. ampl. Rio de Janeiro: Campus, 2004.

HARRINGTON, H. J. Aperfeiçoando Processos Empresariais. São Paulo: MAKRON Books, 1994.

HERRING, J. Business intelligence in Japan and Sweden: Lessons for the US. Journal of Business Strategy, v. 13, n. 2, p. 44-49, 1992.

IKEYA, N.; ISHIKAWA, H. The Japanese intelligence culture. Competitive Intelligence Review, v. 12, n. 4, 51-56, 2001.

KAHANER, L. Competitive intelligence: how to gather, analyze, and use information to move your business to the top. New York: Simon \& Simon \& Schuster, 1998. 300p.

LEGG, S.; HUTTER, M. Universal intelligence: A definition of machine intelligence. Minds and Machines, v. 17, n. 4, p. $391-$ 444, 2007.

LOVELOCK, C.; WRIGHT, L. Serviços: marketing e gestão. São Paulo: Saraiva, 2002.

MENEZES, E. M. Inteligência competitiva: uma revisão de literatura. Revista Digital de Biblioteconomia \& Ciência da Informação, v. 3, n. 1, p. 103-130, 2005.

MERLO VEGA, J. A. El servicio bibliotecário de referencia. Anales de Documentación, Salamanca, n. 3, p. 93-126, 2000.

MILLER, J. Millennium intelligence: understanding and conducting intelligence in the digital age. New Jersey: CyberAge Books, 2000.

MILLER, J. P. O processo de inteligência: como funciona, seus benefícios e sua situação atua. In: MILLER, J. P. O milênio da inteligência competitiva. Porto Alegre: Bookman, 2002, p. 32-52. 
RAMOS, H. C.; CARVALHO, F.; CUNHA, M. B. Avaliação do uso do serviço de respostas técnicas: um serviço de informação destinada à microempresa brasileira. Ciência da Informação, Brasília, v. 35, n. 3, p. 255-269, set./dez. 2006

RODRIGUES, L. C.; RISCAROLLI, V.; ALMEIDA, M. I. R. Inteligência competitiva no Brasil: um panorama do status e função organizacional. Revista Inteligência Competitiva, São Paulo, v. 1, n. 1, p. 63-85, abr./jun. 2011.

ROSSI, J. F. J.; PASSARINI, L. C.; FARIA, L. I. L. Aplicação do software Zotero para apoiar a prática de inteligência competitiva. Revista Digital de Biblioteconomia \& Ciência da Informação, v. 10, n. 1, 2012. Disponível em: $<$ http://www.sbu.unicamp.br/seer/ojs/index.php/rbci/article/view/548>.

ROZADOS, H. B. A informação científica e tecnológica e os serviços de informação. Revista Informação \& Sociedade: Estudos, João Pessoa, v. 16, n. 1, p. 65-82, 2006

SANTOS, E. L.; NASSIF, M. E. Os profissionais de inteligência competitiva no Brasil: habilidades, competências e demandas do mercado. Revista PRISMA.COM, n. 15, p. 1- 24, 2012.

SANTOS, R. N. M. Métodos e ferramentas para gestão de inteligência e do conhecimento. Perspectivas em Ciência da Informação, Belo Horizonte, v. 5, n. 2, p. 205-215, jul./dez. 2000.

SANTOS, R. N. M. Processos, métodos e ferramentas de inteligência competitiva: características, aplicabilidade e limitações. Revista de Biblioteconomia de Brasília, v. 23-24, n. 4, p. 493-508, 2000.

SANTOS, V. F. Resposta técnica: proposta de metodologia para os agentes do SEBRAE da Região Centro-Oeste. Ciência da Informação, Brasília, v. 26, n. 1, p. 28 - 38, jan./abr. 1997.

SILVA, A. B. O. O sistema de informações estatísticas no Brasil e as relações entre seus produtores e usuários. Ciência da Informação, Brasília, v. 34, n. 2, p. 62-69, maio/ago. 2005.

SILVA, E. G. S.; MARINHO, R. R. Serviço de informação: um instrumento para a integração universidade-empresa. In: SEMINÁRIO NACIONAL DE BIBLIOTECAS UNIVERSITÁRIAS, 12., 2002. Recife. Anais... Recife: [s.n.], 2002.

SOUZA, B. A.; SANTOS, E. T. Contribuição dos bibliotecários e cientista da informação no processo de geração de inteligência competitiva nas organizações: visto a partir das publicações nos periódicos da área. Revista ACB, v. 17, n. 2, 2012. Disponível em: <https://revista.acbsc.org.br/racb/article/view/833>

TARAPANOFF, K. (Org.). Inteligência organizacional e competitiva. Brasília: Ed. da UNB, 2001.

TARAPANOFF, K. Informação, conhecimento e inteligência em corporações: relações e complementaridade. In: (Org.). Inteligência, informação e conhecimento. Brasília: IBICT; UNESCO, 2006. p. 19-35.

TRZECIAK, D. S. Modelo de observatório para arranjos produtivos locais. 2009. 234 f. Tese (Doutorado em Engenharia de Produção) - Programa de Pós-Graduação em Engenharia de Produção, Universidade Federal de Santa Catarina, Florianópolis, 2009.

TYSON, K. Guide to competitive intelligence: gathering, analyzing, and using competitive intelligence. Chicago: Kirk Tyson, 1998.

VALENTIM, M. L. P. et al. O processo de inteligência competitiva em organizações. DataGramaZero, Rio de Janeiro, v. 4, n. 3 , p. 1-23, 2003

VARGO, S. L.; LUSCH, R. F. Why "service"? Journal of the Academy of Marketing Science, v. 36, n. 1, p. 25-38, 2007.

XINZHOU, X.; XUEHUI, J. The evolution of competitive intelligence in China. Journal of Intelligence Studies in Business, v. 1 , n. 1, 2011. Disponível em: <https://ojs.hh.se/index.php/JISIB/article/view/15>. 


\section{Dados dos autores}

\section{Gregório Jean Varvakis Rados}

Professor do Departamento de Engenharia e Gestão do Conhecimento, da Universidade Federal de Santa Catarina (EGC/UFSC). Doutor em Manufacturing Engineering - Loughborough University of Technology.

g.varvakis@ufsc.br

\section{Danielly Oliveira Inomata}

Mestre em Ciência da Informação pela Universidade Federal de Santa Catarina. Dutoranda em Ciência da Informação (UFSC).

inomata.danielly@gmail.com

\section{Dorzeli Salete Trzeciak}

Doutora e Mestre em Engenharia de Produção pela Universidade Federal de Santa Catarina (UFSC).

dorzeli@gmail.com

\section{Maurício Cordeiro Manhães}

Mestre e doutor em Engenharia e Gestão do Conhecimento pela Universidade Federal de Santa Catarina (EGC/ UFSC). Professor em Savannah College of Art and Design, Savannah/GA/USA.

manhaes@msn.com

Recebido - Received: 2016-04-27

Aceitado - Accepted: 2016-06-21

i Organização para a Cooperação e Desenvolvimento Econômico.

ii Sistema Mundial de Informação em Ciência e Tecnologia, criado pela UNESCO em 1960.

iii Intangibilidade; heterogeneidade ou variabilidade; inseparabilidade; perecibilidade ou simultaneidade (EDVARDSSON; GUSTAFSSON; ROOS 2005).

iv Associação Brasileira de Analistas de Inteligência Competitiva.

\section{$(c))_{\mathrm{EY}}$}

This work is licensed under a Creative Commons Attribution 4.0

United States License.

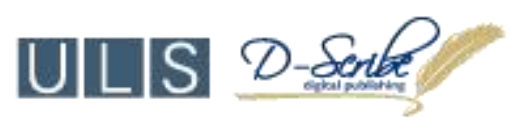

This journal is published by the University Library System of the University of Pittsburgh as part of its D-Scribe Digital Publishing Program and is cosponsored by the University of Pittsburgh Press. 